\title{
Arbor
}

\section{Ciudades milenarias, visitarlas, conservarlas, vivirlas}

Félix del Valle Díaz

Arbor CLXX, 671-672 (Noviembre-Diciembre 2001), 543-558 pp.

Aquella primavera se había adelantado. Suele ocurrir con frecuencia en Toledo. Una mañana, mi madre gritó: «Ya están aquí». Me asomé al patio y vi las golondrinas ocupando su nido como todos los años. Yo me pregunté: «¿serán las mismas?». Mi padre me había dicho que sí; que él las había visto en el otoño mirar atrás cuando se fueron para despedirse y para poder recordar dónde quedaba su casa. Su casa. Yo me sentí inquieto. Pues, ¿no era nuestra aquella casa? Me pasé la mañana pensándolo; y la tarde; y al acostarme aquella noche no me lo pude quitar de la cabeza. Ni he podido aún. ¿Era nuestra aquella casa? ¿O era de las golondrinas que llevarían sabe Dios cuántos siglos habitándola de primavera a otoño? ¿O era tal vez de los siglos que la habían visto ocupar por golondrinas y hombres desde su construcción?

Siembro con esto la duda de las propiedades, pero no de las responsabilidades que, evidentemente, son sólo de los hombres.

Un día hice averiguaciones sobre los anteriores propietarios y, tras otear antiguas escrituras, sólo pude llegar hasta aquel viejo músicosacristán, don Justo, que hacía como hobby órganos cuyas trompetas eran cañas soldadas con cera, y sus fuelles, jay!, hojas de cantorales de pergamino. Y, todos aquellos propietarios, incluidos mis padres, ¿no habrían sido sólo usufructuarios como las golondrinas? Y extendí mi descabellada idea a todas las casas y los vecinos de la vieja ciudad heredada de generación en generación desde hacía cientos de años.

Golondrinas y hombres incidiendo en el tiempo de las ciudades milenarias. Las golondrinas, aportando en su pico las pequeñas porciones de barro para consolidar sus nidos cada año; los hombres, aportando también sus barros a la adaptación de sus casas a sus épocas 
y a sus necesidades. Un puritano se quejaría de estas adaptaciones que han hecho borrar huellas relacionadas con la historia de la humanidad: del «agua va» a los retretes de taza turca con pozos negros y a los inodoros con atarjeas generales. De las cuadras en los bajos del edificio, a los garajes. De las cocinas de leña en el suelo, a las de carbón, petróleo, gas, electricidad... Transformaciones, digo, de las que puede que un puritano se quejara, pero que han venido conservando las casas y los nidos, propiciando su ocupación a través de los siglos. Con esto no me declaro a favor de las transformaciones, tan sólo de las necesarias en los interiores para el desarrollo de la vida de sus moradores, que son los que las mantienen en pie, respetando todo lo posible en lo externo el aspecto de estas viejas urbes. Calles estrechas, torcidas y empinadas, cuyos trazados no podían sospechar la llegada del automóvil, fachadas con huellas romanas, visigodas, árabes, góticas... tampoco pensadas para soportar colgaduras de cables eléctricos o telefónicos, antenas o acondicionadores de aire.

Las necesidades del hombre van cambiando y creciendo a gran velocidad. No es nada fácil adaptar una ciudad milenaria a las necesidades que al hombre le crecen cada día sin romper algo de ella. Por eso no es fácil vivir en una vieja ciudad. Sus habitantes han de soportar toda suerte de incomodidades: vías estrechas por muchas de las cuales no pueden pasar los coches; este elemento que se ha hecho imprescindible en nuestros días y, en las calles donde llegan, imposibilidad por respeto estético en muchos casos de abrir huecos para garajes; dificultad para la colocación de ascensores, de aires acondicionados, etc., necesidades que no les han surgido a las golondrinas.

Las golondrinas. Me estremece pensar que sean las mismas cada año. No recuerdo haber visto nunca una golondrina muerta, lo que me autoriza a imaginar que podrían ser inmortales. De ser así, estas golondrinas, mis vecinas, habrían visto formarse la ciudad hoy milenaria. Y habrían conocido otras gentes: los moradores del cerro del Bú y más tarde las invasiones históricas: romanos, visigodos, árabes... y habrían conocido otros cambios: la conversión de Recaredo y sus súbditos, los judíos afincados en Toledo, las intrigas del conde don Julián, la Conquista, la Reconquista... También la sustitución de la fe cristiana por la mahometana; la del derecho romano y visigodo por el derecho musulmán; la de la lengua latina por la árabe... Y sus vueltas.

Y la creación de los mercados semanales, el Zoco, la agrupación de oficios por calles, los gremios, sus ordenanzas...y habrían visto configurarse los barrios de la ciudad: el judío, los árabes, los mozárabes, el de los francos que trajera Alfonso VI... Y mis golondrinas habrían 
Ciudades milenarias, visitarlas, conservarlas, vivirlas

visto la tolerancia musulmana permitiendo a los cristianos su culto; y los recíprocos privilegios de Alfonso; y las traiciones de su propia esposa y su obispo. Cosas que, entre otras muchas ayudaron a configurar la ciudad, pues sin aquellos cambios nada estaría como hoy, ni sin aquellas tolerancias las mezquitas estarían en pie, ni las sinagogas en sus sitios, ni las iglesias. Ni sin aquellas traiciones estaría la catedral donde hoy la vemos. Esta vieja ciudad y todas las ciudades milenarias con sus comunes vivencias y problemas.

Convendría aclarar antes de seguir, qué es una ciudad milenaria. Otros ya lo han explicado y muy bien. Pero habría además múltiples explicaciones más o menos románticas; aventuremos una: Una ciudad milenaria es una obra de arte hecha por el tiempo y por los hombres. $\mathrm{Su}$ arquitectura, a veces variopinta, ha consolidado un conjunto que siempre es único e inimitable. Por sus recintos, las más veces amurallados, advertiremos su capacidad de defensa y ataque, su religión, su comercio, su trabajo, su descanso... Sus edificios religiosos, civiles o militares, han sido inevitablemente transformados por el poder dominante de turno, o por las necesidades o modas de las épocas que han visto pasar.

Y mientras no nos hemos dado cuenta, o no hemos tenido otros remedios a mano, los hombres hemos transformado estas joyas del pasado. Lo demuestran los vestigios que suele haber, quizá como cicatrices, de todas las épocas y de todos los siglos. Yo sé que lo que voy a decir en un imposible; pero imaginen ustedes que, en Toledo, por ejemplo, pudiéramos contemplar hoy la ciudad romana con su circo completo y sus villas en las riberas del Tajo. Y que en otro lugar, sin haber destruido lo anterior, viésemos hoy la Toledo visigoda, con sus templos arrianos primero y después cristianos, y sus casas y palacios. Encontraríamos, seguro, signos de su monarquía y de sus leyes; su código de Eurico, su Fuero, su Juzgo... Aún me estremezco cuando en alguna fachada o torre diviso alguna de esas piedras visigodas salvadas con tanto acierto por los alarifes árabes o mudéjares. En la fina labra de sus adornos imagino una ciudad de ensueño, muy cercana a la de un cuento de hadas. Y lo mismo me estremezco dolorido sin poder evitarlo, ante un palacio herreriano edificado sobre un palacio árabe, que ante una catedral gótica elevada en el solar de una mezquita que antes hubiera sido iglesia. Repito que no ha sido posible, pero yo quiero soñar que lo hubiera sido y que, en lugar de tener hoy un Toledo sobrepuesto sobre diversos toledos, tuviéramos varios toledos de diferentes épocas que nos pudieran mostrar sus arquitecturas y, a través de ellas, sus culturas $y$ formas de vida. 
Se me podrá decir que una buena parte de la belleza de muchas de estas ciudades antiguas, es la superposición de construcciones, que presenta a nuestros ojos una gran riqueza de arquitecturas de diversos estilos y épocas. Yo contestaría lo dicho: que esto se hizo destruyendo obras anteriores y atropellando con ello a sus autores, y que, de haber podido, habría sido bonito la convivencia de edificaciones pasadas con las que fueron surgiendo en cada época, situadas en diferentes lugares. El único problema para ello habría sido la ocupación del suelo. Pero suelo es lo que sobraba fuera del recinto amurallado; no era por escasez por lo que no se ocupaba más, si no porque la idea de ciudad protegida por murallas llegó hasta el siglo XIX, y no se acabó de desechar definitivamente hasta las guerras del XX. Ya no tiene sentido pretender vivir todos en un recinto protegido ansiando estar a salvo del enemigo y construyendo lo necesario del momento sobre lo anterior. Ya no vemos la necesidad de vivir protegidos todos dentro de murallas.

$\mathrm{Y}$, al ser también más respetuosos con el pasado, hemos llegado a la mayoría de edad en este sentido. El crecimiento de nuestras ciudades milenarias no se realiza ya sobre ellas mismas. Se han creado cinturones en su entorno donde se pueden edificar las nuevas construcciones teniendo en cuenta la vida de hoy. Amplias calles y avenidas que permiten el paso de los coches en dos, en cuatro o más carriles; garajes en las casas, ascensores, cocinas modernas, cuartos de baño con «jacuzzi» y esas cosas, amplios salones donde poder ver la televisión desde las distancias aconsejables, etc., etc.

Ya no es necesario derribar un palacio árabe para elevar una construcción donde ubicar un ayuntamiento, ni una mezquita para elevar una catedral. Por consiguiente, no se derriban casas antiguas para hacer las nuevas. Construyendo las actuales en la periferia se ha creado una nueva ciudad. Ya no es preciso destruir arquitecturas del pasado para hacer las del presente. Yo comprendo que esto deje sin argumentos a ciertos arquitectos jóvenes ilusionados en dejar su obra en una ciudad milenaria entre las de Juan Guas, Enrique Egas, Juan de Herrera, Alonso de Covarrubias... Ilusión comparable a la que cualquier pintor joven podría tener por colgar sus obras en el Louvre, el Prado, la National Gallery... Para eso están los museos de pintura contemporánea que, además de separar épocas, dignifican las obras que en ellos se cuelgan creando los ambientes adecuados a su contemplación. Y para eso están las ciudades nuevas, o los nuevos barrios en las viejas ciudades, donde los nuevos edificios no hacen competencia a otros ni otros se la hacen a ellos.

Estas son las ciudades milenarias. Configuradas, sí, con muestras de las distintas épocas que han pasado por ellas. Yo digo más bien 
Ciudades milenarias, visitarlas, conservarlas, vivirlas

que lamentablemente configuradas con estas muestras. Pero, puesto que ello ya es inevitable, evitemos más adulteraciones y tratemos de conservar para el futuro las ciudades milenarias como están, al tiempo de crear barrios o ciudades de nuestra época para legarlas, también, a nuestros herederos.

Visitarlas. No se puede experimentar el mismo placer visitando una ciudad antigua sin cuidar, que cuando la visita se gira a una vieja ciudad bien cuidada. Hay muchos ejemplos en Europa de estas últimas. También algunos en España. Una ciudad milenaria debe estar siempre atendida y presentar una cara amable a quien la visita. El visitante espera encontrar una ciudad medieval como una isla o un oasis en este comienzo del siglo XXI, donde descanse su vista y su estrés de los estragos que cada día hace en su espíritu su vida cotidiana. Espera encontrar paz en sus calles sin el ruido de un claxon impertinente metiéndose en sus oídos, ni gases de tubos de escape agolpándose en sus fosas nasales.

Le gustaría encontrar una señalización clara que, acorde con la estética que le rodea, le indique dónde está y adónde puede dirigirse. Le sería muy grato encontrar una adecuada iluminación que le permitiera pasear de noche la ciudad y poder contemplar destacados sus principales monumentos, dejando sólo para el recuerdo aquellos viejos refranes de «va más seguro quien no recorre el muro», o «camina más sano quien anda por lo llano», refranes que recuerdan las recomendaciones que se hacían en la Edad Media, de caminar de noche por el centro de la calle, para evitar ser sorprendidos por salteadores apostados en oscuras esquinas o en quicios de puertas.

Un visitante con paladar no espera sólo visitar los museos de la ciudad, espera encontrar también fachadas antiguas pero pulcramente ofrecidas a sus ojos, y rejas de balcones y ventanas bien forjadas y unidas a la «calda», y puertas con nobles maderas reforzadas de regia cerrajería y que, abiertas, les muestren sus patios en los que poder ver sus aljibes y pozos, y sus columnas y ménsulas y canecillos, y las cerámicas antiguas de sus zócalos, y sus bargueños y bancas y otros muebles de épocas pasadas exornándolos y, a través de todo esto, poder otear la vida de sus moradores actuales.

El visitante de nuestras ciudades milenarias acude a ellas como a visitar un museo de vida que él ya no tiene. Y casi siempre todo le parece bien. Aunque haya algunos que, embriagados por ensoñaciones medievales, empiecen a sentir ciertas intransigencias al no hallar exactamente en la vieja ciudad que recorren, lo que a ellos les gustaría encontrar en las escasas horas que dura su visita. Un día conversé 
con un visitante de Toledo que se revelaba contra las transformaciones que él juzgaba innecesarias, pero que, sin embargo, formaban parte de su vida en su ciudad de procedencia. Le dolía tener que dejar paso en una calle estrecha al vehículo de un nativo que venía de trabajar; le dolía encontrar coches aparcados, aunque uno de ellos, por cierto, era el suyo. Se quejaba del tráfico rodado, y de la ropa tendida en algunas ventanas, y de los aparatos de aire acondicionado, y de las antenas, y de los cables, y se quejaba de las palomas y de sus excrementos... Parecía como si se quejara de que en la ciudad que él decía querer tanto, hubiera vida.

Éste era, comprendo, un visitante exigente. Se trataba de un extranjero que decía ser muy amigo del entonces director general de la Unesco, Federico Mayor Zaragoza, al que, dijo, transmitiría sus ideas para «salvar» Toledo. Ideas que evidentemente, según él, no teníamos los toledanos. La mayoría de los visitantes son menos exigentes; comprenden que para que la ciudad que visitan se mantenga, tiene que haber gente viviéndola, poblada de sufridos o gozosos habitantes, según queramos interpretarlo. Con todo, comprendemos lo beneficioso que para los visitantes, los habitantes y las propias ciudades, sería la conjugación de los intereses de estas tres partes, en beneficio del Patrimonio de la Humanidad; siempre teniendo en cuenta que lo verdaderamente importante, es la ciudad milenaria. Sin olvidar, por supuesto, que para mantenerla en pie, le son absolutamente imprescindibles los habitantes; siéndole necesarios, también, los visitantes.

Para hacer la visita agradable a éstos, habrá que procurar que puedan encontrar lo que esperan: una ciudad medieval ubicada en nuestra época. Ello tiene, como sabemos, sus inconvenientes, pues, entre otras cosas, tal vez la primera, habrá que facilitar la llegada de estos visitantes que casi siempre es en coche. Y habrá que atemperar nuestros sueños a la realidad. Si nuestro sueño fuese eliminar por completo el tráfico rodado, para conseguir la ciudad medieval perfecta, nos encontraríamos, en muchos casos, con visitantes a quienes no agradaría tener que subir andando al corazón de la metrópoli y, probablemente, no repetirían su visita ni se la recomendarían a sus amigos. Un porcentaje muy elevado de viajeros es gente de mediana edad para arriba. Viajan mucho los jóvenes, es cierto; pero nuestra población envejece más cada día, afortunadamente, debido a los avances de la Ciencia. Y cada día es más frecuente encontrar en cualquier ciudad grupos de jubilosos jubilados que la visitan.

La imaginación de los ediles deberá entrar en juego buscando fórmulas por las que las viejas ciudades dejen de parecer grandes garajes o aparcamientos y, sin embargo, pueda accederse a ellas en automóviles 


\section{Ciudades milenarias, visitarlas, conservarlas, vivirlas}

que, inteligentemente ocultos en aparcamientos no visibles, hayan podido llevar a sus ocupantes a la ciudad y queden prestos para la salida.

Mi amigo, el referido viajero de aquella conversación, no debería haberse quejado de la ropa tendida en algunos balcones -escasa, por cierto, según mi posterior comprobación-, aunque comprendo sus quejas acerca de cables, antenas, acondicionadores de aire, anuncios comerciales y otros elementos, que aplazamos su mención para el capítulo siguiente reservado al mantenimiento de nuestras queridas viejas ciudades. Y se quejaba, como no, de los coches.

Mantenerlas. Para aquel visitante exigente de mi relato era muy fácil salvar una ciudad milenaria. Bastaba con borrarle la vida; lo cual convertiría su ciudad «salvada» en una ciudad «muerta». De haber sido así, él no podría haber mantenido conversación alguna con un nativo, o sea, conmigo; pues abogaba por una ciudad cual pieza de museo - que no es lo mismo que una ciudad museo- sin gentes en ella; poco más que las señoras de la limpieza que la quitarían el polvo cada mañana antes de abrir sus puertas al turismo.

Pero esa no es la solución. Todos sabemos que una casa deshabitada acaba hundiéndose. Como acabaría una ciudad deshabitada. Para mantener una ciudad en pie debe permanecer viva, con gentes que vigilen y observen cada día sus goteras, y sus revocos y enfoscados, y sus pavimentos, y sus males de piedra... ¡Ay!, sus males de piedra de lo que luego hablaremos, gran problema de las ciudades milenarias, algo menos fácil de resolver que reponer tejas rotas o revocar fachadas.

Sabemos que estos problemas los tienen y los viven los ayuntamientos de estas ciudades antiguas. Y también sus pacientes habitantes, a los que más tarde dedicaremos unas líneas. Estos ayuntamientos están obligados a ser más imaginativos que los de otras ciudades. Y más sensibles y cariñosos con lo que administran. No vamos a dudar de la sensibilidad y cariño de los componentes de cualquier otro concejo, paro habremos de reconocer todos, que a los de las ciudades antiguas les puede haber guiado un especial aprecio por las características de su vieja localidad, lo que les obliga a mantener despierto su interés y su sensibilidad en todo momento mientras dure su «mandato». Obligación y responsabilidad que debe verse acrecentada al momento de conceder licencias de obras en estos viejos recintos, teniendo siempre en cuenta la enorme importancia de su conservación.

Esto de la conservación y el mantenimiento puede parecer bien mientras se trate de casas que no se han caído. Pero, se me podría increpar: ¿y cuando una casa se cae? ¿Se levantará copiando la que hubo, lo cual supondría una falsificación? ¿O se permitirá al arquitecto 
que la eleve hacer su propia obra? Si se levanta una casa completamente caída, rehaciéndola según era, corremos el riesgo de transgredir el artículo 39 punto 2 del título III de la Ley 16/1985, de 25 de junio, del Patrimonio Histórico Español, que dice entre otras cosas:

«En el caso de bienes inmuebles, las actuaciones a que se refiere el apartado anterior irán encaminadas a su conservación, consolidación y rehabilitación y evitarán los intentos de reconstrucción, salvo cuando se utilicen partes originales de los mismos y pueda probarse su autenticidad. Si se añadiesen materiales o partes indispensables para su estabilidad o mantenimiento, las adiciones deberán ser reconocibles y evitar las confusiones miméticas».

En cuanto a evitar la total ruina de una casa, las leyes actuales también son sensibles al caso; veamos si no, el punto 2 del artículo 24 del título II de la citada ley:

«En ningún caso podrá procederse a la demolición de un inmueble, sin previa firmeza de la declaración de ruina y autorización de la Administración competente, que no la concederá sin informe favorable de al menos dos de las instituciones consultivas a las que se refiere el artículo 3».

En cualquier caso, el punto 3 del artículo 21 de esta ley, ya aclara toda posible duda:

«La conservación de los Conjuntos Históricos declarados Bienes de Interés Cultural comporta el mantenimiento de la estructura urbana y arquitectónica, así como las características generales de su ambiente. Se considerarán excepcionales las sustituciones de inmuebles, aunque sean parciales, y sólo podrán realizarse en la medida en que contribuyan a la conservación general del carácter del Conjunto. En todo caso, se mantendrán las alineaciones urbanas existentes».

Está claro que el problema en este caso no es fácil de resolver. $\mathrm{Si}$ se reconstruye una casa según las características anteriores a su caída, se cometerá un delito de falsificación. Pero si se permite a un arquitecto crear su actual obra de forma arbitraría en el solar de la derruida, se estará adulterando la ciudad milenaria; se estará contribuyendo al cambio de su fisonomía, atentando en parte contra el Patrimonio Histórico y avanzando hacia la fecha en que, el ente administrativo que concedió a la ciudad en cuestión el título de "Ciudad Patrimonio de la Humanidad», se lo reclame por haber perdido las razones de su concesión.

Como decíamos antes, habrá arquitectos que digan que una ciudad antigua está compuesta por edificaciones de épocas diversas; y que ellas conforman el conjunto que hoy se admira. Y, basándose en esto, 
Ciudades milenarias, visitarlas, conservarlas, vivirlas

reclamen su derecho a construir en ciudades viejas, donde los arquitectos de otras épocas han construido sin encontrar impedimentos. Unas líneas más arriba he dejado mi opinión a este respecto que, como digo, no es fácil de resolver. Habría que tratar cada caso según su propia naturaleza. No creo que haya una respuesta generalizada. Yo, al menos, no me atrevería a darla.

Como yo mismo me he planteado las preguntas anteriores, difíciles de responder, $y$, ante la imposibilidad de formular una respuesta tajante que sirva a todos los casos, trataré de salirme por la tangente lo más elegantemente posible; es decir: saliéndome del jardín sin pisar las flores, y sin quedar atrapado en su laberinto.

Cuando todos estemos de acuerdo en lo ya dicho, es decir, en que una ciudad antigua es una obra de arte, bastará con tratarla como tal. Hoy todos sabemos que una obra de arte en un museo requiere cuidados especiales: temperaturas adecuadas en las salas de exhibición; humedades relativas del aire precisas a cada caso; iluminación conveniente para que los rayos ultravioleta no perjudiquen pigmentos, soportes y otras materias, etc., etc. Pero además, las piezas que hoy tenemos por obras de arte, tienen, con el beneplácito de todos, conservadores especializados, cuidadores expertos que vigilan constantemente la salud de las obras a ellos encomendadas. Ya hace mucho tiempo que una obra de arte frágil, como puede ser una pintura al óleo sobre lienzo, no se deja arruinar. Ya han pasado a la historia aquellos cuadros colgados en las iglesias que desprendían desconchones de sus superficies bellamente pintadas. Comparar aquellos recuerdos de mi época de monaguillo con el celo que hoy imponen las comisiones de arte diocesano, resulta altamente tranquilizador.

Los museos están dotados de conservadores y de instrumentos que detectan la decadencia de las obras que custodian y, antes de que una obra de arte se arruine, se advierte su estado de deterioro y se detiene restaurándola. Las iglesias, que albergan una buena parte de nuestro patrimonio artístico, tienen y mantienen las mismas responsabilidades. No dispone cada templo del mismo dinero que ingresa cada museo, pero, aunque tal vez insuficientes, no les faltan ayudas estatales, regionales o locales, para cumplir la obligación de mantener, para todos, el patrimonio cultural que custodian.

Cuando se tengan por obras de arte a las ciudades antiguas, cuando las ciudades milenarias sean tenidas por museos donde se exhiben monumentos, edificios y barrios que, por separado o en su conjunto se consideren con el acuerdo unánime obras de arte, se pondrán conservadores a su servicio, que vigilarán y mantendrán su vida. Arquitectos 


\section{Félix del Valle Díaz}

conservadores, especialistas en restauración de edificaciones antiguas, inspeccionarán constantemente edificios eclesiales, militares, políticos y particulares, a fin de detectar en su comienzo cualquier proceso de deterioro e impedirlo mediante la restauración oportuna y adecuada.

A esto es a lo que habría que llegar para no tener que responder a mis preguntas anteriores. Hoy nadie se plantea que sobre un lienzo en el que hubo una pintura de Velázquez, pinte su obra un pintor actual. Hay lienzos vírgenes donde hacerlo. Sin embargo, sí está admitida la restauración de ese presunto lienzo de Velázquez antes de su ruina total. Seríamos más exactos si dijéramos que la restauración en estos casos, más que admitida, está exigida.

Pero antes de disponer de estos conservadores inspeccionando las ciudades milenarias, habría que corregir ciertas cosas, como por ejemplo el tráfico rodado.

Éste es uno de los mayores problemas de las viejas ciudades. Y las razones son varias. La primera es que estas ciudades antiguas no están hechas para los coches; ni los coches para ellas, aunque llenen sus calles y plazas. El automóvil, aunque inventado a vapor en el siglo XVIII y perfeccionado con el motor de explosión en el siglo $\mathrm{XIX}$, ha sido una de las grandes conquistas del XX, siendo, probablemente, la mejor herramienta que el progreso ha puesto en manos del hombre. $\mathrm{Y}$ alrededor de esto está el problema: no se puede ir contra el progreso; no se le puede negar al hombre - aunque viva en una ciudad milenariasu derecho a usar herramienta tan necesaria para el desarrollo de su vida, dejándole en inferioridad con respecto a sus contemporáneos. Pero tampoco se puede permitir que las trepidaciones y la polución que expelen los gases de los vehículos, perjudiquen la integridad de estas gloriosas urbes, además, por supuesto, de lo contradictorio de su presencia en la estética de las ciudades medievales.

Esta gran conquista del progreso, esta valiosísima herramienta para el hombre, que es el coche, está contaminando nuestra atmósfera con los gases de sus tubos de escape. Entre estos contaminantes se cuenta el dióxido de sulfuro como el más peligroso de sus gases. Conviene saber que, según un estudio realizado hace algunos años, en la ciudad de Los Angeles se producían en la atmósfera 400 toneladas diarias de dióxido de sulfuro, lo que supone un enorme peligro para las personas y las cosas y, entre estas cosas, se encuentran los materiales de construcción, siendo a las piedras a las que más puede atacar. Habremos de tener en cuenta que este dióxido de sulfuro, esparcido en el aire, se convierte en ácido sulfúrico al contacto con la lluvia o la niebla, y este ácido, de grandísima corrosividad, ataca muy especialmente a 
Ciudades milenarias, visitarlas, conservarlas, vivirlas

la piedra por su porosidad y porque la humedad relativa del aire mantiene casi siempre sus superficies húmedas, siendo este proceso el mayor responsable de lo que hoy llamamos «el mal de piedra». Y ¡ojo!, lo que hoy afecta a las piedras de las ciudades antiguas, afectará en el futuro a las piedras de las ciudades modernas. La explicación de por qué las piedras de las ciudades antiguas están hoy más perjudicadas por este mal, estriba en el tiempo pasado desde su labra. Sin contar con la diferencia de porosidad o dureza de cada clase de piedra, una piedra recién labrada presenta siempre una superficie menos porosa que aquella que está erosionada desde hace siglos por las inclemencias del tiempo; y estas superficies erosionadas, exentas ya de pulimentos, presentan una porosidad más fácil de penetrar.

No pretendemos decir que los males de las piedras sean debidos sólo a los vehículos de motor. Una parte de su deterioro se debe al natural ataque bioquímico de los microorganismos que, unido al factor biológico ambiental, pueden producir la meteorización de las rocas. Según nos dice el Dr. José María Muñoz Cebrián, en su obra «Biología de los materiales», "las sustancias naturales, cualquiera que sea su origen, naturaleza y estructura, se degradan en más o menos tiempo cuando las condiciones necesarias son favorables». Cuando las condiciones necesarias "para su degradación» son favorables; ésta es la cuestión: hay que impedir en lo posible que las condiciones necesarias a su degradación se produzcan o la favorezcan. A pesar de todo, como sabemos que hay una gran variedad de microorganismos y plantas que por sí solos o relacionados con otras sustancias agresivas son responsables del envejecimiento de las piedras, habremos de procurar que este envejecimiento no se precipite con los baños diarios de ácido sulfúrico. Y, esto es lo difícil: no hay que dejar morir a las piedras, pero hay que conservar la vida en las viejas ciudades, para lo que conviene pensar en no echar de ellas a sus habitantes, procurando compaginar ambos problemas.

¿Les llegará su turno a las piedras que se colocan en las construcciones actuales? Les llegaría si todo siguiera igual. Es decir, si continuásemos contaminando la atmósfera con los mismos procesos, si las chimeneas de nuestras fábricas siguieran expeliendo los mismos gases corrosivos, si se siguieran manteniendo hornos cuya base de funcionamiento sean los carbones y aceites, si los camiones y coches siguieran usando el mismo carburante...

Pero yo mantengo la esperanza de que se descubra, en plazo no muy lejano, un carburante ecológico para vehículos y fábricas, que devuelva a nuestra atmósfera su pureza original. $\mathrm{Y}$ respiren nuestras 
piedras. Y respiren nuestros árboles. Y respiremos los hombres. Y respiren mis vecinas las golondrinas.

Mientras esto llega, y sabiendo que nuestras piedras se deterioran un poco cada día, no estaría de más pensar en la forma de protegerlas lo antes posible, para lo que sólo se nos ocurren dos soluciones; una de ellas ya se ha practicado en nuestros días aunque sin éxito debido a su imperfección, pues se trata de barnices protectores que, al proteger, impiden la respiración de la piedra propiciando la aparición de hongos bajo la capa protectora. Habrá por tanto, que esperar a que la Química dé a luz un producto que proteja de la polución a las piedras e impida la formación de hongos entre capa protectora y elemento protegido. Según nos informa el Dr. Muñoz Cebrián, funciona desde los años 70 el laboratorio «José Luis Escario», que ha hecho grandes avances sobre los problemas de la biodeterioración. Y existe en Gran Bretaña el «International Biodeteroration Centre», así como el «CAB International Mycological Institute», que se ocupan del estudio de la degradación de los materiales, y a quienes se puede recurrir para recabar ciertas soluciones, aunque me temo que, al no haberlo hecho público, no tengan aún la solución a estos casos concretos.

Mas, mientras esto llega, sentimos la urgencia de proteger ciertas joyas en piedra que, heredadas del pasado, adornan nuestras calles, recordándonos con su presencia la obligación que tenemos de legarlas a nuestros herederos. Podría poner muchos ejemplos en todo el mundo, o sólo en España, pero nos limitaremos a dar únicamente tres de nuestra querida Toledo. Entre las numerosas y valiosas portadas de piedra que exornan las fachadas de esta vieja ciudad, queremos mencionar tres por su excelente calidad y por sus diferentes épocas y estilos. Estas son: La portada Plateresca de San Clemente; la portada Manierista del Colegio de Infantes; y la portada Gótica de la Catedral, conocida como Puerta de Los Leones, aunque estos leones sean un añadido posterior. La protección que sugiero, ya insinuada por mí en otra ocasión, y a riesgo de parecer que pretendo atrevidas innovaciones, es la siguiente: colocar sobre estas portadas unas placas de metacrilato que las protejan no sólo de la polución, sino de cualquier otra agresión o robo. Dos de las portadas propuestas ya han sufrido de estas agresiones: la del Colegio de Infantes, la pérdida de un brazo, que se recuperó, propiciado al parecer por una gotera; y la de Los Leones, el robo hace algunos años de alguna de sus pequeñas imágenes góticas, también por fortuna recuperadas.

No obstante lo dicho, creo que la actuación más inmediata debería ser evitar en lo posible las trepidaciones y los gases del tráfico rodado. 
Ciudades milenarias, visitarlas, conservarlas, vivirlas

También es difícil hallar solución a esto. Requiere, pienso, un tacto especial, pues entran en conflicto muchos razonamientos. Tengo el presentimiento de que si se cierra súbitamente y por completo el tráfico en ciertas ciudades antiguas, se las podría exponer a su extinción. Si ya es difícil conseguir románticos dispuestos a habitarlas, soportando los inconvenientes que comporta, habrá que poner cuidado en no incomodarles más, condenándoles a una vida cuasi medieval. En cuanto a la prohibición o no de la totalidad del tráfico, todo dependerá, por supuesto, de las dimensiones del recinto de las ciudades. Siempre habrá algunas, como pueden ser la francesa Carcassonne o la española Albarracín y algunas otras, en las que, dejando el coche fuera de las murallas, se pueda pasear el recinto histórico sin mucho esfuerzo.

Pero no creo que sea éste el caso de nuestras Toledo, Avila o Cuenca, por ejemplo. Las distancias y las cuestas no permitirían a los vecinos acarrear enseres o mercancías, ni trasladar a sus enfermos, o desplazarse con la celeridad que hoy nos impone un ritmo de vida que nos ha venido dado; ni permitiría a los comerciantes atender sus negocios por mucho que se señalaran horas de carga y descarga, pues encontrarían dificultades para otras necesidades como puede ser la entrega domiciliaria al detall. $\mathrm{Si}$ a los inconvenientes que todos conocemos se añaden los de no poder entrar en coche, ni comprar cosas de algún peso en la ciudad, ni a los comerciantes poder hacer sus entregas a domicilio, será una manera sutil de invitarles a salir del recinto amurallado, a los unos y a los otros, en busca de barrios donde no se les haga la vida imposible.

No creo que haya muchas soluciones claras al respecto; pero poniendo buena voluntad por parte de todos, quizá se pueda llegar al resultado de mantener las ciudades milenarias vivas con gente dentro. Hay que contar con que los habitantes de ellas así lo quieren. Y hay que contar con que sus administradores, sus ayuntamientos, quieren tener el tacto preciso para detener el galopante proceso de deterioro que sufren sus ciudades.

Antes de atreverme, tímidamente, a hacer una propuesta al respecto, quiero advertir que si para otros lo ideal fuese que estas ciudades milenarias no tuvieran tráfico rodado a motor, también para mí sería ideal. Pero ya he explicado por qué me parece conveniente un detenido estudio sobre el caso, pues estimo que manteniendo la vida en la ciudad, la mantenemos a ella.

Una solución sería que de las carreteras de circunvalación que rodean a estas viejas ciudades, entraran algunos ramales al recinto antiguo, estratégicamente estudiados, hacia lugares en los que hubiera 
aparcamientos subterráneos; y así, acortando las distancias de aparcamiento en aparcamiento, facilitar a viajeros y habitantes sus desplazamientos peatonales por la ciudad, reservando siempre el derecho a la llegada a garajes particulares que ya estuvieran autorizados, y a los taxis o ambulancias para casos de emergencia.

Sé que no es una solución drástica. Pero es una forma de peatonalizar la vieja urbe, salvo en los ramales indicados, evitando con ello un porcentaje grande de contaminación, de trepidaciones y de ruidos, y el aparcamiento perenne que hasta ahora soportan nuestras estrechas calles, con vehículos llenándolas que impiden el paso a viandantes, las entradas a las casas y el acceso, jay!, a los bomberos o ambulancias en casos necesarios.

Y, hablando de bomberos, no hay que pasar por alto la responsabilidad de prevención de incendios en estas ciudades antiguas, construidas en su mayoría con entramados de viejas maderas de pino sin sangrar, y cuyas calles estrechas facilitarían la propagación de incendios con posibles catastróficas consecuencias que nos hacen recordar dramas como los de Lisboa o Santander. Para curarse en salud, es preciso sembrar las calles de bocas de riego y de hidrantes, y abastecer los parques de bomberos de vehículos capaces de entrar por todas las calles, y proveer las plantillas de personal suficiente y especializado en lo que serían los incendios en estas ciudades; a quienes no bastaría con saber sofocar fuegos, sino que una parte no menos importante de su labor sería la salvación de las obras de arte que suelen llenar los conventos y museos.

Tal vez sea también llegado el momento de revisar las licencias de ciertos anuncios comerciales y de bebidas multinacionales que invaden y afean fachadas y calles; y de, sin negar el derecho al aire acondicionado, obligar a que sus aparatos exteriores se oculten detrás de las rejas de balcones o ventanas bajo las que se habrán colocado previamente tupidas celosías de madera que, al estilo conventual, los oculten. Y es llegado el momento, también, de iniciar el esfuerzo económico que supone la sustitución del cableado aéreo por otro subterráneo. Y de estudiar soluciones a las palomas, estas aves inocentes y amables, que están planteando serios problemas con sus excrementos en torres y monumentos. ¿Anticonceptivos en los piensos? Habría que oír a los ecologistas. ¿Capturas masivas para trasladarlas? Siempre se tendría el peligro de su regreso. ¿Mecanismos de ultrasonido que las ahuyenten? Parece que resultan demasiado caros. Quiero poner aquí el ejemplo de lo efectuado en la torre de Santo Tomé, recién restaurada, en la que se han colocado mallas metálicas en sus ventanas, invisibles desde abajo; y en sus mechinales, un ladrillo vertical para evitar el paso de estas fértiles aves. Se ha cerrado con ello el gran hábitat de las palomas del barrio. 
Ciudades milenarias, visitarlas, conservarlas, vivirlas

Todo es una lúdica invitación a poner en juego la imaginación.

Vivirlas. Ya lo hemos dicho: calles estrechas, edificios sin garajes, pisos sin ascensores, dificultad de tráfico rodado, y algunas cosas más. Pero los que vivimos dentro de estas ciudades soportamos, generalmente, dichas dificultades con paciencia. Sentimos estas ciudades milenarias como nuestras, y las queremos. Tal vez un poco más de lo que puedan quererlas los que las visitan de vez en cuando y tienen en sus ciudades una vida de algún confort vedado a nosotros. Y puede que también un poquito más que nuestros paisanos que viven en los barrios nuevos, aunque sólo sea porque «el roce hace el cariño». Y esto es lo que nos pasa, que aunque reconozcamos los defectos, los soportamos, como se suelen admitir los defectos de los seres queridos. Pero tenemos el corazón de cristal expuesto a romperse por las presiones de un lado, y por las tentaciones de otro.

Hay una constante tentación que acosa a los habitantes de una ciudad milenaria. No están completamente aislados. Las murallas que los rodean tienen sus puertas abiertas y por ellas se les brindan unas formas de vida teñidas para ellos de colores futuristas que son el presente de sus contemporáneos y amigos allende las murallas. Cuando salen de sus recintos y se asoman a la vida de los otros, no pueden evitar ser invadidos por un sentimiento que raya en el complejo de inferioridad. Y, por más que piensen en el privilegio de vivir por donde pasaron el Cid, Alfonso VI o Carlos V, no pueden justificar la resistencia a las sensaciones que producen en sus retinas, acostumbradas a la tenue luz del barrio histórico, las luces de aquellas avenidas y los resplandores de los escaparates de comercios, bares y restaurantes.

Además, mientras en su recinto amurallado escasea la juventud, del otro lado de las murallas siempre hay niños saltando y gritando cuyas risas cantarinas contrastan con el silencio de su viejo barrio. $\mathrm{Y}$ uno vuelve a pensar en el Cid, y en los árabes, y en los judíos... Y regresa a su casa diciéndose a sí mismo que regresa a la paz, a la tranquilidad; nunca se dirá que regresa a la tristeza. Y que, aunque no pueda llegar con su coche a los bajos de su casa y subir en ascensor la compra efectuada en el supermercado del barrio nuevo, se repite mientras hace viajes por su escalera cargado de bolsas, que lo verdaderamente importante es vivir en el casco histórico, y que no le importa que le pongan trabas con el aparcamiento de su coche o al pedir una licencia de obras, y que pague sus contribuciones urbanas como si su casa estuviera situada en el barrio más iluminado y más cercano a aquellas grandes tiendas, y que lo que tenían que hacer todos los habitantes de cascos históricos, sería unirse como hacen los habitantes de algunos poblados de la Costa del Marfil, para evitar 
que el progreso les devore y poder guardar sus tradiciones; y poder seguir soñando con el Cid, Alfonso VI, los árabes y los judíos... Y, a veces, este habitante del viejo barrio, llega a creerse lo que piensa.

Temo haber dado con todo lo dicho una mala impresión acerca de la vida en estos recintos amurallados con calles estrechas, casas sin garajes, y viviendas sin ascensores; donde la noche comienza antes que en otros sitios al dejarse sentir después de ponerse el sol, cuando su escasa iluminación y la ausencia de resplandores de escaparates, no logran vencer la oscuridad. Donde el silencio se hace pastoso cuando los escasos vecinos se encierran en sus casas, dejan de mirar por sus balcones y comienzan a asomarse a las ventanas del mundo por ese oscuro cajón que llaman televisor. Las calles se quedan solas y sin ruidos, y es cuando las pueblan los fantasmas de sus antiguos moradores. $\mathrm{Y}$ es cuando los románticos tienen la ocasión de mezclarse con ellos, pasear con ellos los rincones y soñar con ellos las leyendas que envuelven la historia de las milenarias ciudades.

Temo haberles pintado un paisaje triste y desolador que no sea del todo cierto. Pero tampoco puedo contarles la verdad, mi verdad. Yo vivo en una ciudad milenaria: Toledo. $\mathrm{Y}$ vivo en ella por voluntad propia. Y soy feliz. Reconozco que para contarles cómo es la vida de cualquier ciudadano en un viejo recinto amurallado, tengo que hacer el esfuerzo de salirme de mi personalidad, de mi júbilo: y no puedo ser juez y parte.

Recuerdo que unas líneas más arriba he expresado mi desilusión por que no hayamos podido conservar el Toledo romano, el visigodo, el árabe, etc. $\mathrm{Y}$ al no haber podido conservarlos, me habría gustado mucho haber podido tener alguna imagen de ellos. ¿Alguna fotografía? Pues, sí. Pero yo no pierdo las esperanzas.

Hace algunos días leí en un periódico, hablando de rastreos del cielo, la siguiente noticia:

«...Este programa de observación ha recogido datos de más de 50 millones de galaxias y 2.000 millones de estrellas. El censo ha identificado más de 70 quásares a tan grandes distancias que están siendo vistos aquí y ahora tal y como eran cuando el universo tenía menos del $10 \%$ de su edad actual...»

Y mi esperanza está en que con potentes telescopios, antenas radiotelescópicas, lupas de gran alcance, sofisticados espejos retrovisores y qué sé yo, pueda el hombre un día llegar a ver imágenes de la tierra en diferentes épocas y zonas concretas y, entre estas, localizar y fotografiar imágenes de las viejas ciudades milenarias. Y ver cuándo comenzaron a hacer sus nidos en los patios mis vecinas las golondrinas. 